Journal of Extension Education

Vol. 28 No. 2, 2016

\title{
Biodiversity Implications of Riparian Home-gardens: the Case of Chalakkudy River Based Agro-Ecosystem in Kerala
}

\author{
Allan Thomas ${ }^{1}$, Usha C. Thomas ${ }^{2}$ and N. Kishore Kumar
}

\begin{abstract}
Riparian home-garden farming system are human landscapes that are sustainable, fulfilling the different pillars of socio-economic and environmental stability. This explorative study conducted in the 60 selected home-gardens in the left-right riparian banks of Chalakkudy river in Kerala, India casting the upper reaches and middle to lower reaches aimed to assess the crop diversity of tropical riparian home-gardens in terms of diversity index. Altogether 60 home-gardens were analysed and the Shannon - Wiener index of Biodiversity was found to be 1.518 in the upper riparian reaches and for the middle to lower reaches the average diversity index was 1.453 indicating erosion in biodiversity in home-gardens cascading towards middle to lower reaches of the riparian corridors.
\end{abstract}

Keywords: Biodiversity, Landscapes, Shannon - Wiener index, Ecosystem, Species, Anthropogenic

\section{INTRODUCTION}

Biodiversity describes the variety and array of life on earth. A common measurement of biodiversity is the total number of species found in an area often measured in terms of diversity index. High levels of ecosystem stability is ensured when system is more diverse and that lead to more resilience against extreme weather events, such as floods or drought. Biodiversity gives us choices, options and flexibility to help us cope with variability, including long-term habitat changes. But, riparian (describes the land immediately surrounding water sources where water strongly influences the immediate ecosystem) areas, that support high levels of natural biodiversity is often the niche of intervention, exploitation and ironically the sites of conservation. Historically, riparian areas that were important for natives facilitating early settlements owing to transitions have transcended to dwelling units with agricultural and riparian resource acting as the main resources for making them the ways and means of their life. Home-garden forms the basic farming production system in Kerala, a

$1 \& 2$ Assistant Professors and 3. Professor, College of Agriculture, Kerala Agricultural University, Vellayani, Thiruvananthapuram, Kerala - 695522. 
constituent state of India and is present in all agro-ecological zones. Home-gardens of Kerala supports $2.76 \%$ of India's people (The Hindu, 2013) signifying the importance of this predominant type of agricultural production system.

This system with a repository of highly diversified valuable plants and animals per unit area with inclusive interaction through intervention by man has resulted in a unique combination of high levels of productivity, dependability and sustainability. The same is the case of Kerala riparian home-gardens. Hodgkin (2001) articulated that home gardens contribute to the conservation of biodiversity at the ecosystem, species and within species levels. Under the shrinking per capita land availability, dominance of nucleotide family structure, occupational shifts, resettlement after migration, cultural diversity, coupled with the intricacies of the global and market economy, home-garden systems are mushrooming and at the same time are facing their own challenges. The aesthetic and economic value of the riparian homegarden agro ecosystem facilitates both agricultural and allied interventions with other occupational interferences which is uniquely different from the general garden-land based home-garden farming system. One of the major challenges is its rapid influence of home-gardens in the riparian biodiversity. Hence this study envisaged for a comprehensive study of crop diversity in the riparian homegardens.

\section{METHODOLOGY}

\section{Measure of Diversity Index}

Floristic richness of the Kerala homegardens is quite substantial (Kumar, 2011). In this study, Shannon-Wiener index of diversity based on information theory (the information content is a measure of the amount of uncertainty) was used to calculate the diversity index of the home-gardens. This index was purposively chosen as its measure enables a better understanding of the structural configuration of home-gardens. Also, the whole of a home-garden as a single unit could be considered for the study unlike other cases where usually a portion of the ecosystem is considered by way of further sampling. The formula used for determining the diversity index was :

$$
H^{\prime}=\quad \sum_{i=1}^{s} \quad\left(p_{i} \log _{2} p_{i}\right)
$$

Where,

$$
\mathrm{H}^{\prime} \text { - Shannon-Wiener diversity }
$$
index (Di)

$$
\mathrm{p}^{\mathrm{i}} \text { - A proportion of total sample }
$$
belonging to $i^{\text {th }}$ species

$$
\mathrm{s}=\text { number of species }
$$

\section{Sampling}

A total of 60 riparian home-gardens were enumerated for its crop diversity. 
Biodiversity Implications of Riparian Home-gardens: the Case of Chalakkudy River Based Agro-Ecosystem in Kerala

The sixty samples were selected from the upper reaches, middle reaches and lower reaches of Chalakkudy river at every one $\mathrm{km}$ interval covering both left and right banks of the river covering a total of $30 \mathrm{~km}$ stretch on one side enabling an understanding on the agricultural biodiversity of the entire stretch of the river bank ecosystem.

\section{FINDINGS AND DISCUSSION}

The influence of agricultural activities and home-gardens that caters to the livelihood of farm family has an influence on the riparian ecosystem diversity. Irrespective of the nature of different agroecosystem, Saikia et al. (2012) reported that high diversity and low concentration (density) of dominance in different home-garden categories may

Table 1.

Biodiversity Index of Riparian Home-Gardens in the Upper and Mid to Lower Reaches of Chalakkudy River

index presented for sixty samples of riparian home-gardens selected randomly from the upper and lower reaches are presented in Table 1 .

of the Chalakkudy riparian tracts. The
results are enumerated and discussed
under the following subheads.
Region wise Diversity index (Di) of
riparian home-gardens in the upper of the Chalakkudy riparian tracts. The
results are enumerated and discussed
under the following subheads.
Region wise Diversity index (Di) of
riparian home-gardens in the upper reaches and mid to low reaches

The results of region wise diversity of riparian home-gardens indirectly throwing light to the biodiversity status of the Chalakkudy riparian tracts. The
results are enumerated and discussed
under the following subheads.
Region wise Diversity index (Di) of
riparian home-gardens in the upper of the Chalakkudy riparian tracts. The
results are enumerated and discussed
under the following subheads.
Region wise Diversity index (Di) of
riparian home-gardens in the upper of the Chalakkudy riparian tracts. The
results are enumerated and discussed
under the following subheads.
Region wise Diversity index (Di) of
riparian home-gardens in the upper

be due to variations in anthropogenic pressure in different home gardens. index $(\mathrm{H})$ ) was worked out for a proper understanding of the diversity level

$\mathrm{N}=60$

\begin{tabular}{|c|c|c|c|c|c|c|c|c|}
\hline S1.No. & $\begin{array}{l}\text { Riparian } \\
\text { Reaches }\end{array}$ & \multicolumn{5}{|c|}{ Shannon Diversity index (H') } & Mean $\mathbf{H}^{\prime}$ & $\begin{array}{l}\text { Standard } \\
\text { Deviation }\end{array}$ \\
\hline \multirow{2}{*}{1} & \multirow{2}{*}{$\begin{array}{l}\text { Upper } \\
(n=10)\end{array}$} & 1.235 & 1.614 & 1.674 & 1.457 & 1.414 & \multirow{2}{*}{1.518} & \multirow{2}{*}{0.168} \\
\hline & & 1.709 & 1.765 & 1.366 & 1.45 & 1.491 & & \\
\hline \multirow{10}{*}{2} & \multirow{10}{*}{$\begin{array}{l}\text { Middle to } \\
\text { lower } \\
(n=50)\end{array}$} & 1.492 & 1.161 & 1.58 & 1.292 & 1.573 & \multirow{10}{*}{1.453} & \multirow{10}{*}{0.201} \\
\hline & & 1.350 & 1.384 & 1.632 & 1.522 & 1.593 & & \\
\hline & & 1.193 & 1.243 & 1.193 & 1.632 & 1.502 & & \\
\hline & & 0.873 & 1.535 & 1.537 & 1.696 & 1.182 & & \\
\hline & & 1.177 & 1.362 & 1.537 & 1.215 & 1.720 & & \\
\hline & & 1.254 & 1.649 & 1.561 & 1.579 & 1.592 & & \\
\hline & & 1.425 & 1.114 & 1.633 & 1.472 & 0.932 & & \\
\hline & & 1.614 & 1.521 & 1.736 & 1.432 & 1.636 & & \\
\hline & & 1.337 & 1.666 & 1.449 & 1.553 & 1.535 & & \\
\hline & & 1.481 & 1.599 & 1.653 & 1.529 & 1.539 & & \\
\hline
\end{tabular}


Values in Table 1 reveal that the biodiversity was more in the home-gardens of upper reaches (mean Shannon $\mathrm{H}^{\prime}=1.518$ ) as against the biodiversity measures of mid to lower reaches wherein the mean Shannon $\mathrm{H}^{\prime}$ value was 1.453 .

The values of the table also revealed that the Shannon biodiversity $\left(\mathrm{H}^{\prime}\right)$ of home-gardens ranged from 1.235 to 1.765 in the upper riparian reaches; wherein 60 per cent (Table 2) of home-gardens were categorised as low biodiversity homegardens with mean as the check. In case of home-gardens stretching across the mid to lower reaches of the tributaries of Chalakkudy river, the Shannon $\mathrm{H}^{\prime}$ value ranged between 0.873 and 1.736 and 52 per cent of riparian home-gardens were categorised as higher biodiveristy homegardens (52\%) with its mean value as the check as presented in Table 2 .

The values from Table 1 and 2 reveal that, when more percentage of high biodiversity home-gardens was found in lower reaches of the stream, whereas more percentage of lower diversity homegardens appeared in the upper reaches. This could be because more number of home-gardens appeared in mid to lower reaches of the river and were small holdings when compared to the homegardens in the upstream, that were less in number and larger in size when compared to the riparian home-gardens in the lower reaches. Also, the smaller holding size of home-gardens may have more number of taxonomically distinct crops in position as compared to that of larger holding size of home-gardens that may include more number of species of a dominating variety with high economic value.

Region wise Diversity index (Di) of riparian home-gardens in the right and left banks of Chalakkudy river.

Chalakkudy river is unique with man intervention through the river diversion project splitting the river into right and left banks. This has led to unique forms of human landscapes dominated

Table 2.

Categorisation of Region wise Diversity Index (H') of Riparian Home-Gardens (Upper and Mid to Low Reaches)

\begin{tabular}{|c|l|c|c|}
\hline S1.No. & \multicolumn{1}{|c|}{ Category } & $\begin{array}{c}\text { Upper Reaches } \\
\mathbf{n = 1 0}\end{array}$ & $\begin{array}{c}\text { Middle to Lower } \\
\text { reaches } \\
\mathbf{n = 5 0}\end{array}$ \\
\hline 1 & Mean H' & 1.518 & 1.453 \\
\hline 2 & High biodiversity home-gardens & $4(40 \%)$ & $26(52 \%)$ \\
\hline 3 & $\begin{array}{l}\text { Low biodiversity home- } \\
\text { gardens }\end{array}$ & $6(60 \%)$ & $24(48 \%)$ \\
\hline
\end{tabular}


Biodiversity Implications of Riparian Home-gardens: the Case of Chalakkudy River Based Agro-Ecosystem in Kerala

Table 3.

Biodiversity Index of Riparian Home-Gardens in the Right and Left Banks of Chalakkudy River

$\mathrm{N}=60$

\begin{tabular}{|c|c|c|c|c|c|c|c|c|}
\hline S1.No. & Riparian & \multicolumn{5}{|c|}{ Shannon Diversity index (H') } & $\begin{array}{c}\text { Mean } \\
\mathbf{H}^{\prime}\end{array}$ & Standard \\
\hline \multirow[b]{4}{*}{1} & \multirow{4}{*}{$\begin{array}{l}\text { Right bank } \\
(n=20)\end{array}$} & 1.235 & 1.614 & 1.674 & 1.457 & 1.414 & \multirow{4}{*}{1.518} & \multirow{4}{*}{0.168} \\
\hline & & 1.492 & 1.161 & 1.580 & 1.292 & 1.573 & & \\
\hline & & 1.35 & 1.384 & 1.632 & 1.522 & 1.593 & & \\
\hline & & 1.193 & 1.243 & 1.193 & 1.632 & 1.502 & & \\
\hline \multirow{8}{*}{2} & \multirow{8}{*}{$\begin{array}{l}\text { Left bank } \\
(n=40)\end{array}$} & 1.709 & 1.765 & 1.366 & 1.45 & 1.491 & \multirow{8}{*}{1.453} & \multirow{8}{*}{0.201} \\
\hline & & 0.873 & 1.535 & 1.537 & 1.696 & 1.182 & & \\
\hline & & 1.177 & 1.362 & 1.537 & 1.215 & 1.72 & & \\
\hline & & 1.254 & 1.649 & 1.561 & 1.579 & 1.592 & & \\
\hline & & 1.425 & 1.114 & 1.633 & 1.472 & 0.932 & & \\
\hline & & 1.614 & 1.521 & 1.736 & 1.432 & 1.636 & & \\
\hline & & 1.337 & 1.666 & 1.449 & 1.553 & 1.535 & & \\
\hline & & 1.481 & 1.599 & 1.653 & 1.529 & 1.539 & & \\
\hline
\end{tabular}

with home-gardens. The biodiversity index of home-gardens in both banks were worked out and categorised. The results of the same are presented in Table 3 and Table 4 repectively.

The results of region wise diversity index reveal that the biodiversity was more in the left banks (mean Shannon $H^{\prime}=1.518$ ) than the right banks wherein the mean Shannon $\mathrm{H}^{\prime}$ value was 1.453. The values in Table 3 reveal that the biodiversity $\mathrm{H}$ ' range of home-gardens in the right banks ranged from 1.161 to 1.674; wherein 55 per cent (in table 4) were home-gardens with low biodiversity with mean as the check.
In case of home-gardens stretching across the left banks of chalakkudy river, the Shannon $\mathrm{H}^{\prime}$ value ranged between 0.873 and 1.765. The values in Table 4 revealed that 51.67 per cent of riparian homegardens were categorised as higher biodiveristy home-gardens with its mean value as the check. Hence, it could be inferred from Table 4 that both banks consisted of more number of high biodiversity home-gardens. This does not mean that majority of the home-gardens were highly diversified as this kind of categorisation as high and low has been made based on the mean value of its overall biodiversity as a check and moreover such a 
Table 4.

Categorisation of Region wise Diversity Index (Di) of Home-Gardens in the Right and Left Banks

\begin{tabular}{|c|l|c|c|}
\hline S1.No. & \multicolumn{1}{|c|}{ Category } & \multicolumn{1}{|c|}{$\begin{array}{c}\text { Right Bank } \\
\mathbf{n = 2 0}\end{array}$} & $\begin{array}{c}\text { Left Bank } \\
\mathbf{n = 4 0}\end{array}$ \\
\hline 1 & Mean H' & 1.518 & 1.453 \\
\hline 2 & $\begin{array}{l}\text { High biodiversity home- } \\
\text { gardens }\end{array}$ & $11(55 \%)$ & $31(51.67 \%)$ \\
\hline 3 & $\begin{array}{l}\text { Low biodiversity home- } \\
\text { gardens }\end{array}$ & $9(45 \%)$ & $29(48.33 \%)$ \\
\hline
\end{tabular}

type of conclusion can be made only while making comparisons with other studies on biodiversity.

$\mathrm{H}^{\prime}$ ranges from 1.235 to 1.765 in the upper riparian reaches with the average $\mathrm{H}^{\prime}$ of 1.518 and for the middle to lower reaches the mean $\mathrm{H}^{\prime}$ value ranged between 0.873 and 1.736 with an average diversity index of 1.453 is an indication of erosion of biodiversity in home-gardens cascading towards middle to lower reaches of the riparian corridors. This highlights the fact that anthropogenic interventions were more in the mid to lower reaches indicating the necessity of policy intervention to regulate unscrupulous interventions that affect biodiversity adversely, and there is a need to reclaim the biodiversity of the riparian region with more sound agro-forestry programmes.

The better $\mathrm{H}^{\prime}$ in the upper reaches revealed that irrespective of the size of holdings the home- gardens tends to preserved the maximum taxonomically distinct variance within the region. This also has a reflection of the complementary exploitation of habitat resulting in more complete capture of resources. Such complementarities have been reported by Campbell et al. (1991). In addition to these, influence of management has also been reported by Thomas (2004). As the middle to lower reaches were more dense, home-garden farmers could have being intervened to capacitate his garden with more number of specific imperative and remunerative species, intentionally and thus lowering the biodiversity in the lower reaches .

Considering the nature of selection of home-gardens for the study these values cannot be a representative of the home-gardens for whole of Kerala as these were home-gardens selected from a specific 
type of useful and a unique type of agro-ecosystem that is riparian in its characteristics. However, there was a notion that agroforestry crops are on the decline in home-gardens which was a clear indication of cut and removal of the same for inclusion of economic dominant crops or as a result of spatial pressure due to the constraints of family compulsions. This is resulting in the overall decline of biodiversity in home-gardens which in real is negating the thinking of Das and Das (2005) who had described that home-gardens are the sites of conservation of a large diversity of plants both wild and domesticated, because of their multipurpose uses to the households. Riparian homegardens need to be studied extensively and continuously as these are the owners and conservers of this river based ecosystem that is being widely exploited by man in multiple ways.

\section{CONCLUSION}

The study has shown that there is a trend towards depleting biodiversity in the home gardens of middle to lower reaches of Chalakkudy river. River based home-gardens are just not natural reservoirs or repositories of terrestrial biodiversity, but also the aquatic biodiversity. The diversity of crops with primary home-garden components along with vegetation, livestock, fisheries and other specialisations enables continuous produces/products and reduces the production risks that in turn keeps up the motivation level of farmers to try out with more of commodity crops-non commodity crops combination. This will ensure remunerativeness as well as maintain or augment biodiversity of the riparian agroecosystem.

\section{REFERENCES}

Campbell, D.D., Grines, J.P. \& Mackey, G.N. (1991). A Trade off Between Scale and Precision in Resource Foraging. Ecology 87:532-538

Das T. \& Das A. K. (2005). Inventorying Plant Biodiversity in Home-gardens: A Case Study in Barak Valley, Assam, North East India. Current Science, 89 (1): 155-163.

Hodgkin. (2001). Home Gardens and the Maintenance of Genetic Diversity. Home Gardens and in situ Conservation of Plant Genetic Resources in Farming Systems, Proceedings of the Second International Home Gardens Workshop, 17-19 July 2001, Witzenhausen, Federal Republic of Germany. p: 14-18.

Kumar, B.M. (2011). Species Richness and Aboveground Carbon Stocks in the Home-gardens of Central Kerala, India. Agriculture, Ecosystems and Environment, 140: 430-440. 
Saikia, P.S., Bora, D., Goswami, A., Mudoi, D.K \& Gogoi, A. (2012). A Review on the Role of Azospirillum in the Yield Improvement of Non Leguminous crops. African Journal of Microbiology Research. 6(6) 10851102
The Hindu. (2013 May 18) Kerala Census: Child Population Declines.

Thomas, A. (2004). Technology Assessment in the Home-garden Systems. Unpublished Ph.D. Thesis. Kerala Agricultural University, Thrissur. 173 